\title{
Speed analysis of motorcycle's wheel drive in various road conditions
}

\author{
Wan Muhd Syarifuddin Wan Bukhari ${ }^{1}$, Siti Fauziah Toha ${ }^{1}$, Rabiatuladawiah Abu Hanifah ${ }^{1}$, \\ Nor Azam Kamisan ${ }^{2}$ \\ ${ }^{1}$ Department of Mechatronics Engineering, Faculty of Engineering, International Islamic University Malaysia, Kuala Lumpur, Malaysia \\ ${ }^{2}$ Pumar Solar Power Sdn. Bhd., Seremban, Malaysia
}

\begin{tabular}{l} 
Article Info \\
\hline Article history: \\
Received Feb 19, 2021 \\
Revised Jan 10, 2022 \\
Accepted Jan 24, 2022 \\
\hline
\end{tabular}

Keywords:

Electric vehicles

Road accidents

Road transportation

Vehicle safety

Velocity control

\begin{abstract}
The usage of the motorcycle as a mode of transportation has led to increased energy consumption in the transportation sector and high emissions of greenhouse gases. Thus, the rapid development of electric motorcycles through the advancement of technology provides the possibility to address the issues of high energy consumption and the emission of pollutants. Despite its convenience in accommodating mobility in an urban area, statistical data show that road accidents involving the motorcyclist in Southeast Asian Nations (ASEAN) countries are very high. The contributing factor to the worrying situation is the failure in controlling the motorcycle speed. One of the solutions is by adjusting the motorcycle speed according to different road conditions. However, a shortcoming is identified based on the numerous studies conducted relating to the electric motorcycle where the studies exclude an analysis of electric motorcycle speed when travelling on different road conditions. Therefore, the slip ratio on the front and the rear wheel has been studied to analyze the suitable electric motorcycle speed when driven on different road conditions. An emphasis is made on two road conditions: dry and wet, and the simulation reveals the suitable speed range for the motorcycle under both road conditions.
\end{abstract}

This is an open access article under the CC BY-SA license.

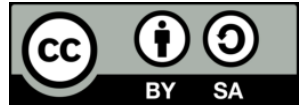

\section{Corresponding Author:}

Siti Fauziah Toha

Department of Mechatronics Engineering, Faculty of Engineering, International Islamic University

Malaysia, Gombak St., 53100, Selangor, Kuala Lumpur, Malaysia

Email: tsfauziah@iium.edu.my

\section{INTRODUCTION}

In urban areas, the motorcycle can be seen as the primary mode of transportation among road users, especially in Asian countries such as Malaysia, China, and Taiwan. Taking Malaysia as an example, according to the Road Transport Department Malaysia, the number of registered motorcycles contributes to almost $45.98 \%$ of the total registered vehicles by the end of 2015 [1]. The number is expected to increase further in the coming years as the public sentiment, especially in the urban area, is hugely affected by the cost of travelling from and to the home daily [2]. Evidently, according to the latest report in June 2017, the number of motorcycles has increased to almost $6.93 \%$ from 2015 [3].

Globally, with the increasing number of motorcycles and other vehicles on the road, the transportation sector has become the main contributor to air pollution and worsening the environment by the increase in greenhouse gas emissions [4]. As the dominant vehicle in the transportation sector, the motorcycle is contributing to almost $10 \%$ of air pollutants in Taiwan [5]. As part of mitigation measures in environmental protection, the government aims to lessen the number of emissions coming from greenhouse gas (GHG) and air pollutants produced from vehicles [6]. It has been studied that lower noise pollution, 
zero-emission of GHG and $75 \%$ reduction of $\mathrm{CO}_{2}$ emission can be achieved through electric motorcycles which consequently act as an effective environmental mitigation measure in the urban area [7], [8].

The electric vehicle is more appealing to the consumer in low-power usage as it is a more cost-effective and more energy-efficient vehicle [9]. The development of low-powered electric vehicles at the moment has been focusing on an electric motorcycle (EM) due to the pressure exerted from the energy crisis as well as the worsening environmental impact caused by the usage of motorcycles in an urban area [7]. Indeed, the researchers have shown that EM is highly efficient for energy consumption as compared to the internal combustion engine motorcycle (ICEM) with the energy efficiency of EMs is about $40 \%$ more than gasoline motorcycles [10]. Even though the electrifying the vehicle can significantly contribute to the reduction of air and noise pollution, it does not add to a lower number of the motorcycle on the road regardless of electric or the conventional motorcycles. The road fatality is found to be the highest in Malaysia as compared to other association of Southeast Asian Nations (ASEAN) countries with 50\% fatalities in road accidents involving motorcyclists [10]. Numerous studies identify human factors as the cause of the accident [11]-[13].

Carelessness, distraction, inexperienced drivers as well as the failure of controlling speed are some of the human errors that contribute to a road accident [14], [15]. However, there are also other causes for a road accident in which relate to vehicle defects such as mechanical failures, tire, and brake defects as well as many different potential reasons [16], [17]. The road environment also can add the potential factors to cause the road accident by the presence of an adverse condition of weather, road, and traffic [18], [19]. Increasing road fatalities and injuries are mostly caused by the failure of motorcyclists in adjusting the speed of motorcycles during monsoon season on wet road conditions. It is indeed, for dry or wet bare roadway, an increase in accident rate is very significant as the tire friction reduces [20]. The incidences are caused by the high slip ratio on wet conditions as compared to the dry road.

Slip is generally given as a percentage of the difference between the surface speed of the wheel compared to the speed between axis and road surface. According to [21], the factors of the relation between slip ratio and different road conditions have been disregarded in the few existing research on two-wheel electric motorcycle dynamics. The climatic condition in Malaysia in which experiences frequent monsoon and sunny days has been included as part of the case study in this paper. In the research conducted by [22], an accident prediction model is developed in the hope to reduce the motorcycle casualty on Malaysia's primary road. The model is established to provide a proper and systematic road geometry as well as traffic census inventory for Malaysia's road planning. On the other hand, a real test of ICEM has been conducted by the West Virginia University Institute of Technology to assess the performance of ICE motorcycles travelling on the dry road [23]. A similar assessment was conducted at the University of Lisbon on the Saldanha electric motorcycle to observe the speed of the vehicle in urban road conditions [24]. It is acknowledged that not all disasters are preventable but their impacts including all the underlying risks can be reduced.

Hence, in this study, the models of the motorcycle are developed to investigate the maximum and suitable speed range of the motorcycle on the dry and wet roadway. Both ICEM and EM models of motorcycles are included to be under this study. The suitable speed range of the motorcycles is investigated as a means to ensure the stability of the motorcycle as the slip ratio varies according to road conditions. This paper consists of the modelling of motorcycles in section 2 . In section 3, the simulation design is presented, and the discussion is presented in section 4 . Finally, in section 5, the conclusion serves as a summary of the findings.

\section{MODELLING OF MOTORCYCLES}

\subsection{Internal combustion engine motorcycle (ICEM)}

The development of an internal combustion engine motorcycle or ICEM requires important functional components such as generic engine, torque converter, inertia block, simple gear, nonlinear rotational damper, differential, vehicle body, and tires. The generic engine model acts as a reference to supply power to the ICEM. The torque of the engine can be generated from the throttle of the motorcycle. The equations for the generic engine are shown as (1)-(7). Next, the torque converter is connected to the generic engine. The torque converter has an impeller shaft as an input and turbine shaft as an output whereas the equations for the torque converter are shown as (8)-(12).

$$
\begin{aligned}
& P\left(\Omega, T_{e}\right)=T_{e} g(\Omega) \\
& T_{e}=\frac{P}{\Omega}=\left(\frac{P_{\max }}{\Omega_{0}}\right)\left(\frac{p(w)}{w}\right) \\
& p(w)+p_{1} t w+p_{2} w^{2}-p_{3} w^{3} \\
& p_{1}+p_{2}-p_{3}=1
\end{aligned}
$$




$$
\begin{aligned}
& p_{1}+2 p_{2}-3 p_{3}=0 \\
& \pm w=\frac{1}{2}\left(-p_{2} \pm\left(p_{2}^{2}+4 p_{1} p_{3}\right)^{\left(\frac{1}{2}\right)}\right. \\
& w=\frac{\Omega}{\Omega_{0}} \\
& R_{w}=\frac{w_{T}}{w_{I}} \\
& R_{T}=\frac{T_{T}}{T_{I}} \\
& K=w_{I} /\left(T_{I}^{\frac{1}{2}}\right) \\
& R_{T}=R_{T} R_{w} \\
& K=K\left(R_{w}\right)
\end{aligned}
$$

The input and output of the torque converter are connected with the inertia block. The inertia block is used to ensure the motorcycle is accelerated in positive a direction. The equation for the inertia block is shown as (13). Then, the torque converter is connected to the simple gear. The gear ratio can be varied by using simple gear. The equation for simple gear is shown as (14). The simple gear equation shows the relationship between the number of teeth of the follower on gear and the number of teeth of the base on gear. Furthermore, the nonlinear rotational damper works as coupling, drives and damper. The equation for nonlinear rotational damper is shown as (15). Based on the equation, it shows a relationship between the damping torque and angular velocity. The output from the nonlinear rotational damper is connected with the differential. The differential will allow the driven shaft to move or to rotate with varying velocity. The equation for the differential is shown as (16).

$$
\begin{aligned}
& T=J \frac{d w}{d t} \\
& g_{F B}=r_{F} / r_{B}=N_{F} / \\
& T_{D}=b_{1} w+\operatorname{sign}(w) \cdot b_{2} w^{2}+b_{3} w^{3}+\operatorname{sign}(w) \cdot b_{4} w^{4}+b_{5} w^{5} \\
& w_{D}=(1 / 2) g_{D}\left(w_{S 1}+w_{S 2}\right)
\end{aligned}
$$

The proposed model for the vehicle body of the motorcycle is shown in Figure 1. The vehicle body is being modeled with longitudinal dynamics and motion. The equations for the vehicle body are shown as (17)-(22). By modeling the (17)-(22), the normal force acting on the tire and speed of the motorcycle can be identified.

$$
\begin{aligned}
& m_{x}=F_{x}-F_{d}-m g \cdot \sin \beta \\
& F_{x}=n\left(F_{x f}+F_{x r}\right) \\
& F_{d}=C_{d} p A\left(V_{x}-V_{w}\right)^{2} \cdot s g n\left(V_{x}-V_{w}\right) \\
& F_{z f}=\frac{-h(F d+m g \sin \beta+m \dot{V} x) b \cdot m g \cos \beta}{n(a+b)} \\
& F z r=\frac{+(F d+m g \sin \beta+m \dot{V} x) b \cdot m g \cos \beta}{n(a+b)} \\
& F_{z f}+F_{z r}=m g \frac{\cos (\beta)}{n}
\end{aligned}
$$

The study on vehicle dynamic behavior requires the presence of a tire model [25]. The magic formula tire model has been introduced by Pacejka, whereby this particular tire model is used for the analysis of tire behavior when driving on different road conditions since it is capable to deal with different slip conditions. The capability of the model in dealing with different slip conditions is majorly influenced by the retrieval of data on the tire force, tire moments, aligning torque, and longitudinal force. The equations for the 
magic formula tire model are shown as (23). The coefficient used in magic formula is $\mathrm{B}, \mathrm{C}, \mathrm{D}$, and $\mathrm{E}$ where $\mathrm{B}$ is stiffness factor, $\mathrm{C}$ is shape factor, $\mathrm{D}$ is peak value and $\mathrm{E}$ is curvature factor. The summary of symbols used in this modeling section is listed in Table 1.

$$
F_{x}=f\left(k, F_{z}\right)=F_{z} D \sin (C \arctan (B k-\arctan (B k)))
$$

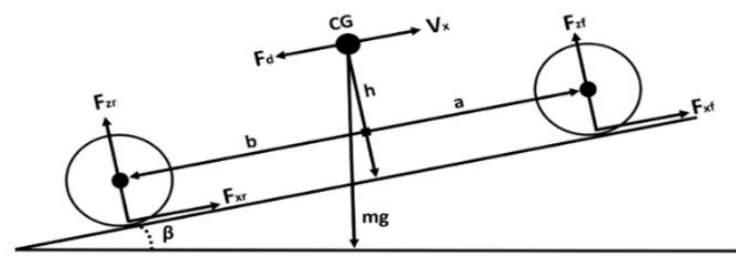

Figure 1. Proposed model vehicle body of motorcycle

Table 1. Parameters of ICEM and EM systems

\begin{tabular}{|c|c|c|c|c|c|}
\hline Symbol & Parameter of ICEM system & Unit & Symbol & Parameter of EM system & Unit \\
\hline$V_{x}$ & longitudinal vehicle velocity & $\mathrm{km} / \mathrm{hr}$ & $R_{o n}$ & resistance on bridge & $\Omega$ \\
\hline$T$ & inertia torque & $\mathrm{Nm}$ & $V_{o}$ & nominal voltage & $\mathrm{V}$ \\
\hline$T_{e}$ & engine torque & $\mathrm{Nm}$ & $v_{b}$ & back emf & V \\
\hline$T_{D}$ & damping torque & $\mathrm{Nm}$ & $k_{v}$ & back emf constant & - \\
\hline$p_{1}, p_{2}, p_{3}$ & power demand coefficient & - & $T$ & torque & $\mathrm{Nm}$ \\
\hline$g(\Omega)$ & engine power demand coefficient & - & $T_{E}$ & electromagnetic torque & $\mathrm{Nm}$ \\
\hline$\Omega$ & engine speed & $\mathrm{rpm}$ & $k_{t}$ & torque constant & \\
\hline$R_{w}$ & speed ratio & - & $i$ & motor current & A \\
\hline$w_{T}$ & turbine angular speed & $\mathrm{rad} / \mathrm{s}$ & $V$ & battery voltage & V \\
\hline$w_{I}$ & impeller angular speed & $\mathrm{rad} / \mathrm{s}$ & $V_{\text {ref }}$ & reference voltage & V \\
\hline$R_{T}$ & torque ratio & - & $V_{\min }$ & minimum reference voltage & $\mathrm{V}$ \\
\hline$K$ & capacity factor & - & $V_{\max }$ & maximum reference voltage & V \\
\hline$J$ & inertia & $\mathrm{kg} \cdot \mathrm{m}^{2}$ & $v_{b}$ & back EMF & V \\
\hline$g_{F B}$ & follower-base gear ratio & - & $k_{v}$ & back emf constant & - \\
\hline$N_{F}$ & number of teeth of follower on gear & -- & $\alpha, \beta$ & curve-fitting constant & - \\
\hline$N_{B}$ & number of teeth of base on gear & & $D$ & duty cycle & - \\
\hline$b_{1}$ & damping coefficient & - & $H_{0}$ & input voltage to $\mathrm{H}$-bridge & $\mathrm{V}$ \\
\hline \multicolumn{6}{|l|}{$b_{2}, \ldots, b_{5}$} \\
\hline$w_{D}$ & angular velocity of longitudinal driveshaft & $\mathrm{rad} / \mathrm{s}$ & $V_{p w m}$ & $\begin{array}{l}\text { pulse width modulation } \\
(\mathrm{PWM}) \text { voltage }\end{array}$ & $\mathrm{V}$ \\
\hline$w_{S 1}, w S_{2}$ & angular velocity of the sun gears 1 and 2 & $\mathrm{rad} / \mathrm{s}$ & $A_{p w m}$ & amplitude of PWM signal & - \\
\hline$m$ & vehicle mass & $\mathrm{kg}$ & $I_{\text {out }}$ & output current & A \\
\hline$V_{w}$ & headwind speed & $\mathrm{km} / \mathrm{hr}$ & $T_{1}, T_{2}$ & $\begin{array}{l}\text { torque on input and output } \\
\text { shaft }\end{array}$ & $\mathrm{Nm}$ \\
\hline$h$ & number of wheels on each axle & - & & $\begin{array}{l}\text { power on the input and output } \\
\text { shaft }\end{array}$ & W \\
\hline$F_{x f}, F_{x r}$ & $\begin{array}{l}\text { longitudinal forces on each wheel at the front and rear } \\
\text { ground contact points }\end{array}$ & $\mathrm{N}$ & & gear ratio & - \\
\hline$F_{z f,} F_{z f}$ & $\begin{array}{l}\text { normal load forces on each wheel at the front and rear } \\
\text { ground contact points }\end{array}$ & $\mathrm{N}$ & & & \\
\hline$\beta$ & inclination angle & degree & & & \\
\hline$a$ & $\begin{array}{l}\text { distance of front axles from the normal projection of } \\
\text { vehicle } C G \text { in the common axle }\end{array}$ & $\mathrm{m}$ & & & \\
\hline$b$ & $\begin{array}{l}\text { distance of rear axles from the normal projection of vehicle } \\
\text { CG in the common axle }\end{array}$ & $\mathrm{m}$ & & & \\
\hline$n$ & number of wheels on each axle & - & & & \\
\hline$A$ & effective frontal vehicle cross-sectional area & $\mathrm{m}^{2}$ & & & \\
\hline$C_{d}$ & aerodynamics drag coefficient & - & & & \\
\hline$p$ & mass density of air & $\mathrm{kg} / \mathrm{m}^{3}$ & & & \\
\hline$B$ & stiffness factor & - & & & \\
\hline$C$ & shape factor & - & & & \\
\hline$D$ & peak value & - & & & \\
\hline$E$ & curvature factor & - & & & \\
\hline$F_{x}=f\left(k, F_{z}\right)$ & longitudinal force exerted on the wheel at the contact point & $\mathrm{N}$ & & & \\
\hline$F_{z}$ & vertical load on wheel & $\mathrm{N}$ & & & \\
\hline
\end{tabular}

\subsection{Electric motorcycle (EM)}

The required components to develop EM are quite similar to ICEM by which the electric motorcycle or EM also has a nonlinear rotational damper, inertia block, differential, vehicle body, and tires. However, there are slight differences in developing the EM model where the additional components are the controlled 
PWM voltage, H-bridge, DC motor, and gearbox. In addition, the generic engine is replaced by a generic battery. The power to run the EM is produced by the generic battery where batteries are the fundamental components in every electronic application. The equation for the generic battery is shown as (24). The nominal voltage and ampere-hours $(\mathrm{AH})$ rating input can be varied.

$$
V=V_{o}\left[1-\left(\frac{\alpha(1-x)}{1-\beta(1-x)}\right)\right]
$$

Next, the controlled PWM voltage will receive the voltage from the generic battery. The PWM voltage is determined based on the reference voltage. As a result, the demanded duty cycle can be calculated. The equation for the demanded duty cycle is shown as (25). Then, controlled PWM voltage is connected with the H-bridge. The H-bridge is used as a motor driver. The H-bridge will accept the PWM voltage as an input. The equation for the H-bridge is shown as (26).

$$
\begin{aligned}
& D=100 \times\left(\frac{\text { Vref }-V \min }{V \max -V \min }\right) \% \\
& H_{o}=\frac{V \cdot V_{p w m}}{A_{p w m}}-I_{\text {out }} R_{\text {on }}
\end{aligned}
$$

The DC motor is connected to the output of the H-Bridge. The DC motor is modeled with two characteristics namely electrical and torque. The equations for DC motor are shown as (27)-(31).

$$
\begin{aligned}
& v_{b}=k_{v} w \\
& T_{E}=k_{t} i \\
& T_{E} w=v_{b} i \\
& k_{t} i w=k_{v} w i \\
& k_{v}=k_{t}
\end{aligned}
$$

Lastly, the gearbox functions as a gear ratio. The gear ratio is the ratio between the input shaft and output shaft angular velocity. The input and output connections of the gearbox are connected to the inertia block in order to ensure the motorcycle accelerates in a positive direction. The equations for the gearbox are shown as (32)-(35). Table 1 summarizes the parameters used for modeling the EM.

$$
\begin{aligned}
& w_{1}=N \cdot w_{2} \\
& T_{2}=N \cdot T_{1} \\
& P_{1}=w_{1} \cdot T_{1} \\
& P_{2}=-w_{2} \cdot T_{2}
\end{aligned}
$$

\section{SIMULATION DESIGN}

All the equations in section 2 are converted into a Simulink block diagram. The type of generic engine used in the ICEM system is a spark-ignition engine whereby its power demand coefficient (p1, p2, and p3), is set by 1 . In the subsystem, the gear ratio can be adjusted by varying the number of teeth of the base on gear, NB and number of teeth of follower on gear, NF. Furthermore, the rotation of the output shaft can be selected either in the opposite or in a similar direction towards the input shaft by using the simple gear. For this system, a selection is made whereby rotation of the output shaft moves in the same direction towards the input shaft.

In designing the EM system, it is similar to the ICEM system with the differences in the system design of EM as compared to ICEM is the generic battery, controlled PWM voltage, H-bridge, DC motor and gearbox subsystem. In the EM system is a generic battery which is significant in supplying battery nominal voltage, Vo, and is controlled by PWM voltage to loads likes DC motor based on the reference voltage. The EM system includes the gearbox to allow a variety of gear ratio combinations. The input and output parameters of the models are shown in Table 2. 
Table 2. Parameters of simulation for ICEM and EM system

\begin{tabular}{clc}
\hline Symbol & \multicolumn{1}{c}{ Parameter } & Value and unit \\
\hline$g$ & gravitational acceleration & $9.81 \mathrm{~m} / \mathrm{s}^{2}$ \\
$\beta$ & inclination angle & $0^{0}$ \\
$V_{w}$ & headwind speed & $0 \mathrm{~km} / \mathrm{hr}$ \\
$m$ & ICEM mass & $165 \mathrm{~kg}$ \\
& EM mass & $80 \mathrm{~kg}$ \\
$h$ & height of vehicle CG above the ground & $0.5 \mathrm{~m}$ \\
$a$ & distance of front axles, respectively, from the normal & $1.4 \mathrm{~m}$ \\
& projection point of vehicle CG in the common axle & \\
$b$ & distance of rear axles, respectively, from the normal & $1.6 \mathrm{~m}$ \\
& projection point of vehicle CG in the common axle & \\
$n$ & number of wheels on each axle & 1 \\
$A$ & effective frontal vehicle cross-sectional area & $3 \mathrm{~m}^{2}$ \\
$C_{d}$ & aerodynamic drag coefficient & 0.4 \\
$p$ & mass density of air & $1.18 \mathrm{~kg} / \mathrm{m}^{3}$ \\
$V_{o}$ & nominal voltage & $72 \mathrm{~V}$ \\
$x$ & ratio of ampere-hours (AH) left to the number of AH & $60 \mathrm{AH}$ \\
$V_{\min }$ & minimum reference voltage & $0 \mathrm{~V}$ \\
$V_{\max }$ & maximum reference voltage & $72 \mathrm{~V}$ \\
$k_{v}$ & back emf constant & $7.2 \mathrm{e}-5^{150}$ \\
$N$ & gear ratio & 10 \\
$b_{1}, b_{2}, \ldots b_{5}$ & damping coefficient & $10 \mathrm{e}-5,0,1 \mathrm{e}-6$ \\
$P_{\max }$ & maximum power from the engine & $1.0 \mathrm{e}+5 \mathrm{~W}$ \\
$\Omega$ & engine speed & $800 \mathrm{rpm}$ \\
$p_{1}, p_{2}, p_{3}$ & power demand coefficient for spark-ignition engine & $1,1,1$ \\
$g_{F B}$ & follower-base gear ratio & 2 \\
\hline & &
\end{tabular}

\section{RESULT AND DISCUSSION}

In the simulation, both motorcycle models are exposed to different road conditions namely, dry, and wet, to investigate the effect of these conditions on to slip ratio of the motorcycle. Figure 2 (a) illustrates the results of the ICEM and EM front and rear wheel slip ratio on a dry road. From this figure, for the front wheel of ICEM, the slip ratio is initially recorded at 62.83 before slowly declining and remains constant at a slip ratio of 0.035 . For the rear wheel slip ratio of ICEM, the slip ratio is recorded to be 16.87 initially before finally remaining constant with a slip ratio of 0.002 .

While for the EM on the dry road, on the front wheel the slip ratio at the beginning is recorded at 0 before a slight increase to 0.27 at 0.02 seconds and gradually decreases and remains constant with 0.058 . For the rear wheel slip ratio of EM, the slip ratio only shows a slight increase from 0 initially to finally remain constant at 0.00167 . Both the ICEM and EM are then simulated under the wet road condition and are documented in Figure 2 (b). Based on Figure 2 (b), the slip ratio of the front wheel of ICEM is sharply declined when initially peaked at 62.83 before finally remaining constant at 0.157 . Whereas the final value of the ICEM's rear-wheel slip ratio is at 0.072 when initially is recorded at 21.07 during the beginning of the simulation.

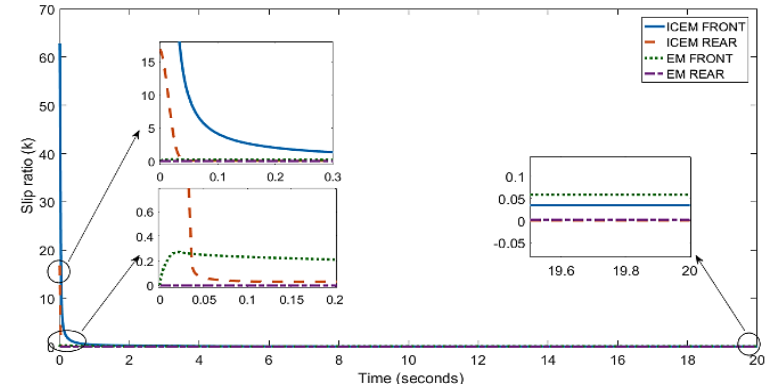

(a)

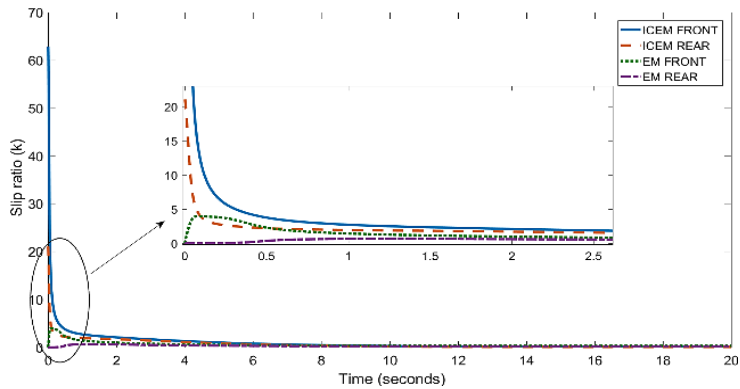

(b)

Figure 2. ICEM and EM front and rear wheel slip ratio on (a) dry road and (b) wet road

On the other hand, the front wheel slip ratio of EM is recorded at 0 initially with a slight increase in the value of 3.93 between 0 and 0.07 seconds before gradually decreases and remain stable at a ratio of 0.304. For the rear wheel slip ratio of EM, the slip ratio started at a ratio of 0 and a slight increase to 0.64 at 1.23 seconds before gradually declined and settled at a slip ratio of 0.2 . From the Figures 2 (a) and 2 (b), the 
slip ratio for ICEM on the front and rear wheel for both road conditions shows that the slip ratio for ICEM is higher than EM.

The speed profiles of both ICEM and EM under a dry road condition are shown in Figure 3 (a) whereas Figure 3 (b) illustrates the speed profile of both systems when subjected to wet and dry road conditions. In terms of the vehicle's speed, under the dry road condition, the ICEM is able to reach up to $91.32 \mathrm{~km} / \mathrm{h}$ while the EM managed to rise to the speed of $74.77 \mathrm{~km} / \mathrm{h}$ within the 20 seconds of the simulation time. When the systems are subjected to the wet road condition, the speed of the ICEM is observed to reach to $82.55 \mathrm{~km} / \mathrm{h}$ while the speed of the EM is noted to reach $64.96 \mathrm{~km} / \mathrm{h}$.

Note that the speed of the ICEM is higher than the speed of the EM since the slip ratio is inversely proportional to the friction coefficient and directly proportional to motorcycle speed. The higher the slip ratio, the higher the motorcycle speed. Furthermore, the graph pattern for slip ratio of both ICEM and EM on dry and wet road conditions indicates a similar pattern as through time, the slip ratio slowly remains stable. As the slip ratio is stable, the motorcycle will reach a steady condition and a suitable motorcycle speed when driven on dry and wet road conditions.

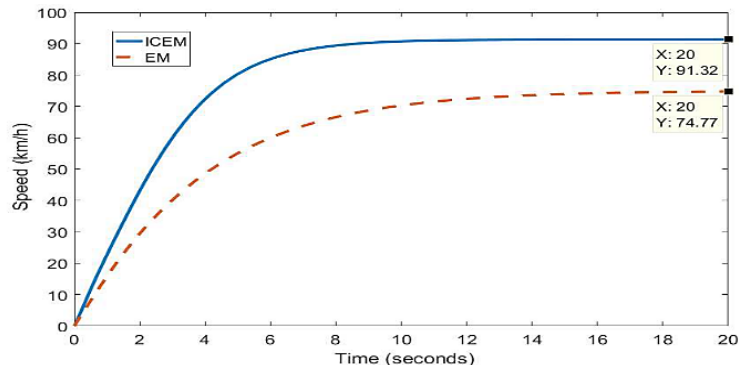

(a)

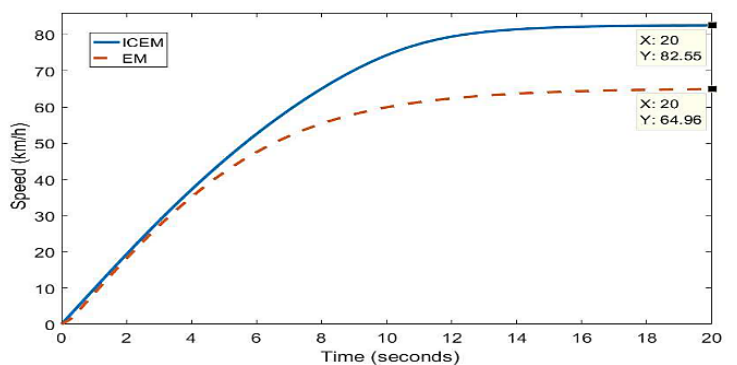

(b)

Figure 3. ICEM and EM speed on (a) dry road and (b) wet road

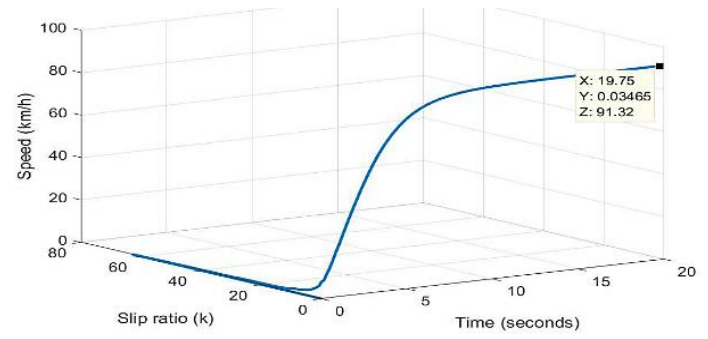

(a)

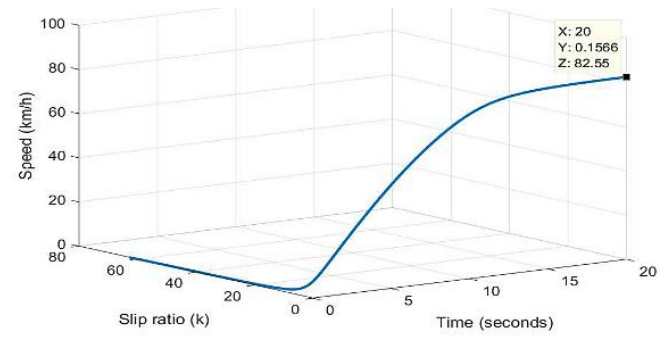

(b)

Figure 4. Relationship between slip ratio and speed of ICEM through the time on (a) dry road and

(b) wet road

To acquire an understanding in regard to the relationship between slip ratio and motorcycle's speed through the times, the three-dimensional (3D) graphs are being shown in Figures 4 (a), 4 (b), and 5 (a), 5 (b). Through all those 3D figures, it can be observed that within the same time frame the slip ratio of both ICEM and EM reach a constant value. The slip ratios are recorded to increase stably until the maximum speed is reached. Based on these findings, in the dry road condition, the maximum speed the ICEM can travel is around 91.32 $\mathrm{km} / \mathrm{h}$ while the maximum speed of EM is approximately $74.77 \mathrm{~km} / \mathrm{h}$. In the wet condition, the maximum speed is less for both motorcycles with the maximum speed for ICEM is $82.55 \mathrm{~km} / \mathrm{h}$ and EM is $64.96 \mathrm{~km} / \mathrm{h}$.

From Figure 4 (a), at the maximum speed on the dry roadway, the slip ratio is recorded at 0.035 while in Figure 4 (b) at the maximum speed on the wet roadway, the slip ratio is observed at 0.157 . A higher slip ratio on the wet roadway is expected as the tire friction reduces in this road condition. The same evidence can be seen in the case of EM. In Figure 5 (a), at the maximum speed on the dry road the slip ratio is recorded at 0.058 whereas in Figure 5 (b) at the maximum speed on the wet roadway, the slip ratio is recorded at 0.304 , a higher value than the slip ratio on a dry road. It is expected that the slip ratio of the vehicle is much higher on the wet roadway as the tire friction reduces in this road condition. 


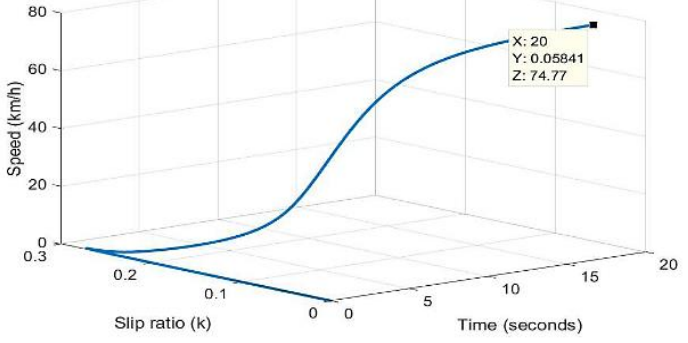

(a)

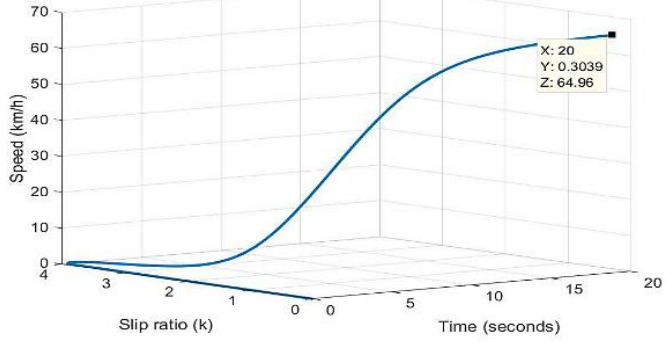

(b)

Figure 5. Relationship between slip ratio and speed of EM through the time on (a) dry road and (b) wet road

\section{CONCLUSION}

There are numerous studies have been attentively reviewed and studied to provide an explicit explanation in regards to the suitable speed range of ICEM and EM when driven on dry and wet road conditions. From this study, it can be concluded that the maximum speed range for ICEM to travel on a dry road condition is up to $91.32 \mathrm{~km} / \mathrm{h}$ whereby the calculated speed for wet road conditions is $82.55 \mathrm{~km} / \mathrm{h}$. Meanwhile, for EM, the maximum speed when driven on a dry road condition is found to be $74.77 \mathrm{~km} / \mathrm{h}$ as compared to when driven on a wet road condition which is $64.96 \mathrm{~km} / \mathrm{h}$.

\section{ACKNOWLEDGEMENTS}

Authors would like to express their gratitude to International Islamic University Malaysia (IIUM) for providing facilities to conduct this research and acknowledge financial assistance from the International Islamic University Malaysia under the IRF19-026-0026 Highly Efficient Li-Ion Battery Recycling with capacity-sorted optimisation for secondary energy storage system.

\section{REFERENCES}

[1] A. J. Nor Azmi, "JPJ Malaysia-Summary of Registered Drivers and Vehicles," 2013.

[2] M. M. Abdul Manan, A. Várhelyi, A. K. Çelik and H. H. Hashim, "Road characteristics and environment factors associated with motorcycle fatal crashes in Malaysia," IATSS Research, vol. 42, no. 4, pp. 207-220, 2018, doi: 10.1016/j.iatssr.2017.11.001.

[3] J. Lee, "Vehicle registrations in Malaysia hit 28.2 million units," Paul Tan's Automotive News (blog), 2017.

[4] R. A. Hanifah, S. F. Toha, S. Ahmad, and M. K. Hassan, "Swarm-Intelligence Tuned Current Reduction for Power-Assisted Steering Control in Electric Vehicles," in IEEE Transactions on Industrial Electronics, vol. 65, no. 9, pp. 7202-7210, September 2018, doi: 10.1109/TIE.2017.2784344.

[5] C.-H. Lu, Y.-R. Hwang, and Y.-T. Shen, "Modeling and Simulation of a Novel Pneumatic Hybrid Motorcycle," International Journal of Green Energy, vol. 9, no. 6, pp. 467-486, September 2012, doi: 10.1080/15435075.2011.622022.

[6] J. Clairand, J. Rodríguez-García, and C. Álvarez-Bel, "Smart Charging for Electric Vehicle Aggregators Considering Users' Preferences," in IEEE Access, vol. 6, pp. 54624-54635, 2018, doi: 10.1109/ACCESS.2018.2872725.

[7] T. L. Mou, W. P. Kin, W. H. Cheong, L. Hangyuan, and X. Zhengchao, "A Case Study on Testing and Performance Evaluation of Electric Motorcycles to Discuss the Environmental Impact of Urban Area in Macao," 2013 Third International Conference on Intelligent System Design and Engineering Applications, 2013, pp. 9-12, doi: 10.1109/ISDEA.2012.9.

[8] Y. Ahn, C. Jun, and H. Yeo, "Analysing driving patterns of electric taxi based on the location of charging station in urban area," 2016 IEEE International Smart Cities Conference (ISC2), 2016, pp. 1-6, doi: 10.1109/ISC2.2016.7580836.

[9] S. Ruensumruay, W. Pattaraprakorn, V. Chutiprapat, and P. Bhasaputra, "The study on the effect of electric motorcycle to energy consumption in Thailand," 2016 13th International Conference on Electrical Engineering/Electronics, Computer, Telecommunications and Information Technology (ECTI-CON), 2016, pp. 1-4, doi: 10.1109/ECTICon.2016.7561407.

[10] M. M. Abdul Manan and A. V'arhelyi, "Motorcycle fatalities in Malaysia," IATSS Research, vol. 36, no. 1, pp. 30-39, July 2012, doi: 10.1016/j.iatssr.2012.02.005.

[11] M. F. Musa, S. A. Hassan, N. Mashros, "The impact of roadway conditions towards accident severity on federal roads in Malaysia," PLoS One, vol. 15, no. 7, pp. 1-12, 2020.

[12] T. Hassan, M. Vinodkumar, and N. Vinod, "Role of sensation seeking and attitudes as mediators between age of driver and risky driving of Powered Two Wheelers," Journal of Safety Research, vol. 62, pp. 209-215, September 2017, doi: 10.1016/j.jsr.2017.06.019.

[13] T. Zhang, F. Hajiseyedjavadi, Y. Wang, S. Samuel, X. Qu, and D. Fisher, "Training interventions are only effective on careful drivers, not careless drivers," Transportation Research Part F: Traffic Psychology and Behaviour, vol. 58, pp. 693-707, October 2018, doi: 10.1016/j.trf.2018.07.004.

[14] M. Fararouei, Z. Sedaghat, S. J. Sadat, and G. Shahraki, "Risk factors for being the at-fault driver: A case-control study," Traffic Injury Prevention, vol. 18, no. 3, pp. 262-266, April 2017, doi: 10.1080/15389588.2016.1244604.

[15] N. Che-Him et al., "Factors Affecting Road Traffic Accident in Batu Pahat, Johor, Malaysia," Journal of Physics: Conference Series, vol. 995, no. 1, p. 012033, 2018. 
[16] M. Solah et al., "Private vehicle roadworthiness in malaysia from the vehicle inspection perspective," Journal of the Society of Automotive Engineers Malaysia, vol. 1, no. 3, 2017.

[17] C. Xu, C. Wang, Y. Ding, and W. Wang, "Investigation of extremely severe traffic crashes using fault tree analysis," Transportation letters, vol. 12, no. 3, pp. 149-156, 2020, doi: 10.1080/19427867.2018.1540146.

[18] J. B. Edwards, "The temporal distribution of road accidents in adverse weather," Meteorological applications, vol. 6, no. 1, pp. 59-68, March 1999, doi: 10.1017/S1350482799001139.

[19] A. K. Jägerbrand and J. Sjöbergh, "Effects of weather conditions, light conditions, and road lighting on vehicle speed." SpringerPlus, vol. 5, no. 1, p. 505, 2016, doi: 10.1186/s40064-016-2124-6.

[20] C.-G. Wallman and H. Åström, "Friction measurement methods and the correlation between road friction and traffic safety: A literature review," Swedish National Road and Transport Research Institute, Tech. Rep., 2001.

[21] T. Abumi and T. Murakami, "Slip ratio control considering road condition for Two-Wheel drive electric motorcycle," 2014 10th France-Japan/8th Europe-Asia Congress on Mecatronics (MECATRONICS2014-Tokyo), 2014, pp. 53-57, doi: 10.1109/MECATRONICS.2014.7018598.

[22] M. M. A. Manan, T. Jonsson, and A. V'arhelyi, "Development of a safety performance function for motorcycle accident fatalities on Malaysian primary roads," Safety Science, vol. 60, pp. 13-20, December 2013, doi: 10.1016/j.ssci.2013.06.005.

[23] B. B., Slater, T. Dinh, B. Frazier, and F. Zabihian, "Electric motorcycle analysis," ASEE 2014 Zone I Conference, pp. 1-3, 2014.

[24] M. Mendes, "On-road evaluation of conventional and electric motorcycle and bicycles performance in urban context," Ph.D. dissertation, Master's Thesis, Instituto Superior Técnico, Lisbon, Portugal, 2013.

[25] M. S. Burhaumudin, P. M. Samin, H. Jamaluddin, R. A. Rahman, and S. Sulaiman, "Modeling and validation of magic formula tire model," in International Conference on the Automotive Industry, Mechanical and Materials Science (ICAMME'2012), Penang, pp. 113-117. May 2012.

\section{BIOGRAPHIES OF AUTHORS}

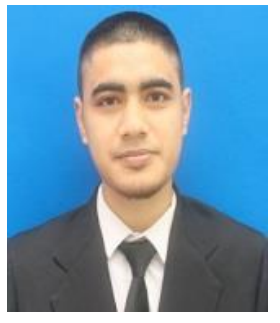

Wan Muhd Syarifuddin Wan Bukhari (D) IS SC $\mathrm{P}$ was born in Selangor, Malaysia. He received the B. Eng (Hons) in Mechatronics Engineering from International Islamic University Malaysia in 2015 and 2019 respectively. The nature of his degree involved a great deal of independent research, requiring initiative, self-motivation and a wide range of skills. His research interest is in the area of control system and electric vehicle. He also an active member of Mechatronics Student Association in International Islamic University Malaysia as he holds a position as financial controller. He can be contacted at email: wmsyarifuddin@ gmail.com.

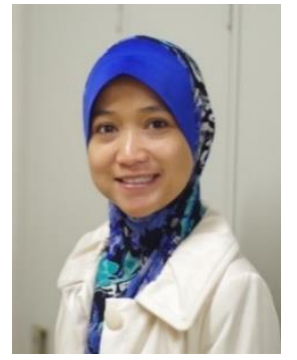

Siti Fauziah Toha (iD SC S P is currently an Associate Professor at the Department of Mechatronics Engineering, International Islamic University Malaysia (IIUM). She received B. Eng (Hons) in Electrical and Electronics Engineering from University Technology Petronas and later received MSc from Universiti Sains Malaysia in electrical engineering. She was then completed her Ph.D in Automatic Control and Systems Engineering from The University of Sheffield in 2010. Dr Toha is a senior member of IEEE and also a Professional Engineer in Malaysia as well as a Chartered Engineer with Engineering Council, The Institution of Engineering and Technology, United Kingdom. She is also an active member of Young Scientist Network, Academy of Sciences Malaysia (YSN-ASM). She can be contacted at email: tsfauziah@iium.edu.my.

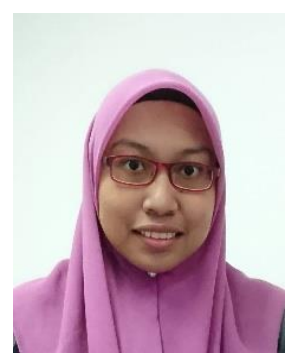

Rabiatuladawiah Abu Hanifah (D) SC P was born in Kuala Lumpur, Malaysia. She received the B. Eng (Hons) in Mechatronics Engineering and M.Sc degrees in Mechatronics Engineering from International Islamic University Malaysia in 2011 and 2014 respectively. In 2020, she successfully graduated and completed her Ph.D in International Islamic University Malaysia researching on the enhancement of complex controller optimization for the electric vehicle. Her research interests are in system controller parameter and performance optimization using various computational intelligence methods. Dr. Rabiatul is a student member of IEEE and also a registered graduate engineer of Board of Engineers Malaysia. In ITEES, IEEE Transactions journals and other scientific publications, she has served as invited reviewer. She can be contacted at email: rabiatul.hanifah@gmail.com.

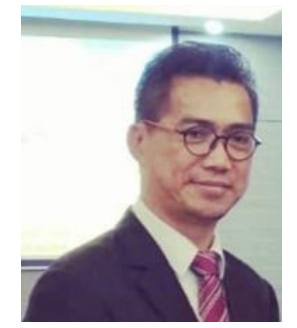

Nor Azam Kamisan (D) BS SC P is currently designated as the CEO of PUMAR Solar Power Sdn, Bhd. He receives his B.Eng in Material Hydrodynamic from Akita University of Japan, Japan in 1999. Later, he pursues his MSc. in Business Studies/Administration/Management from the University of Technology MARA, Malaysia in 2012. With his 14 years of experience in business management, he had held a position in numerous prominent corporations in Malaysia including LANDMARC International Properties Sdn Bhd, AMK IKKYU Corporation Sdn Bhd, HONDA MALAYSIA Sdn Bhd and Perodua Manufacturing Sdn Bhd. He can be contacted at email: norazam.kamisan@gmail.com. 